\title{
Effect of lipid-rich plant extract on the fatty acids composition and meat quality of Belgian-Blue cross bred steers
}

\author{
E J Kim ${ }^{1}$, R I Richardson ${ }^{2}$, M R F Lee ${ }^{1}$, K Gibson $^{2}$, N D Scollan ${ }^{1}$
}

${ }^{1}$ Institute of Biological, Environmental and Rural Sciences, Aberystwyth University, Aberystwyth, SY23 3EB, United Kingdom, ${ }^{2}$ Division of Farm Animal Science, Department of Clinical Veterinary Science, University of Bristol, Langford, BS40 5DU, United Kingdom

Email:kik@aber.ac.uk

Introduction We have previously demonstrated the ability of a lipid-rich plant extract to enhance levels of polyunsaturated fatty acid (PUFA) in beef (Kim et al., 2008). The plant extract (PX) is developed from the liquid fraction extracted from fresh lucerne (Medicago sativa L.), and then heat-treated and dried. The PX has a high degree of rumen protection. This study investigated the effect of incremental inclusion of PX in steers fed on grass silage relative to concentrate on the fatty acid composition of beef and meat quality. Effects of additional vitamin E within the concentrate were also investigated.

Materials and methods Following summer grazing on perennial ryegrass/white clover swards, forty Belgian-Blue $\times$ Holstein steers ( $400 \mathrm{~kg}$ liveweight) were allocated to one of five dietary treatments: 1) grass silage ad libitum (GS), 2) grass silage ad libitum plus 75 g PX/dry matter intake (DMI; GS-LPX), 3) grass silage ad libitum plus 150 g PX/DMI (GSHPX), 4) restricted barley straw and control concentrate (40:60 on a DM basis; S-CC), and 5) restricted barley straw and concentrate with PX (25\% in concentrate on a DM basis) (40:60 on a DM basis; S-PXC) and additional vitamin E ( 300 $\mathrm{mg} / \mathrm{kg}$ ). The PX was manufactured by Désialis-France Luzerne, France. Liveweight was monitored every 28 days and the liveweight gain was used to modify feed intake of the S-CC and S-PXC animals to achieve a similar growth rate to those fed on ad libitum forage. Animals were slaughtered when they achieved fat class 3 and samples of longissimus thoracis et lumborum were taken at $48 \mathrm{~h}$ post-mortem for fatty acid analysis, vitamin E analysis, 10-d aged samples for shelf life studies in modified atmosphere packs. An analysis of variance was conducted with diet as the main factor using GenStat (11th edition) statistical software.

Results Liveweight gain, conformation score and fatness score were similar across diets averaging 1.1 kg/d, 76.7 and 56.5, respectively. Small differences in carcass weight were noted (Table 1). Total fatty acids and amounts of the major saturated fatty acids were not different (Table 1). Feeding grass silage relative to concentrate increased deposition of n-3 relative to n-6 PUFA. Incremental PX on grass silage resulted in additional deposition of 18:3n-3 (and 18:2n-6) and longer chain derivatives EPA and DHA resulting in improvements in P:S and n-6:n-3 ratio. Additional vitamin E in the diet of SPXC increased its content in muscle impacting on lipid stability (TBARS).

Table 1 Animal performance, fatty acid composition (mg/100 g muscle) of longissimus thoracis et lumborum, and TBARS and vitamin E content of muscle in Belgian-Blue cross bred steers given experimental diets

\begin{tabular}{|c|c|c|c|c|c|c|c|}
\hline & GS & GS-LPX & GGS-HPX & S-CC & S-PXC & s.e.d. & $\mathrm{P}$ \\
\hline Right-side cold carcass $(\mathrm{kg})$ & $169^{\mathrm{ab}}$ & $174^{\mathrm{b}}$ & $170^{\mathrm{ab}}$ & $177^{\mathrm{b}}$ & $165^{\mathrm{a}}$ & 3.8 & 0.032 \\
\hline Total fatty acids & 2551 & 2510 & 2433 & 2532 & 1999 & 379.3 & NS \\
\hline $16: 0$ & 665 & 623 & 596 & 654 & 488 & 107.6 & NS \\
\hline $18: 0$ & 325 & 332 & 339 & 344 & 274 & 57.2 & NS \\
\hline $18: 1 n-9$ & 880 & 850 & 794 & 825 & 581 & 134.8 & NS \\
\hline CLA $($ cis -9, trans -11$)$ & 12.9 & 14.4 & 14.1 & 14.7 & 13.4 & 2.46 & NS \\
\hline $18: 2 n-6$ & $56.7^{\mathrm{a}}$ & $70.2^{\mathrm{ab}}$ & $72.7^{\mathrm{b}}$ & $121.3^{\mathrm{c}}$ & $134.5^{\mathrm{c}}$ & 7.37 & $<0.001$ \\
\hline $18: 3 n-3$ & $26.9^{\mathrm{a}}$ & $38.3^{\mathrm{b}}$ & $41.3^{\mathrm{b}}$ & $13.8^{\mathrm{a}}$ & $35.7^{\mathrm{b}}$ & 3.05 & $<0.001$ \\
\hline $20: 5 n-3$ (EPA) & $14.3^{\mathrm{bc}}$ & $16.1^{\mathrm{cd}}$ & $18.3^{\mathrm{d}}$ & $9.8^{\mathrm{a}}$ & $12.3^{\mathrm{b}}$ & 0.79 & $<0.001$ \\
\hline $22: 6 n-3$ (DHA) & $2.42^{\mathrm{bc}}$ & $2.28^{\mathrm{b}}$ & $2.77^{\mathrm{c}}$ & $1.58^{\mathrm{a}}$ & $1.63^{\mathrm{a}}$ & 0.176 & $<0.001$ \\
\hline $\mathrm{P}: \mathrm{S}$ ratio & $0.08^{\mathrm{a}}$ & $0.11^{\mathrm{ab}}$ & $0.13^{b}$ & $0.13^{\mathrm{b}}$ & $0.23^{\mathrm{c}}$ & 0.018 & $<0.001$ \\
\hline$n-6: n-3$ ratio & $1.83^{\mathrm{b}}$ & $1.69^{\mathrm{ab}}$ & $1.62^{\mathrm{a}}$ & $6.28^{\mathrm{c}}$ & $3.36^{\mathrm{c}}$ & $0.049 *$ & $<0.001$ \\
\hline Vitamin E (mg/kg muscle) & $3.86^{\mathrm{ab}}$ & $4.41^{\mathrm{b}}$ & $4.16^{\mathrm{b}}$ & $3.17^{\mathrm{a}}$ & $7.75^{\mathrm{c}}$ & 0.373 & $<0.001$ \\
\hline TBARS, d10 (mg/kg muscle) & $0.59^{\mathrm{ab}}$ & $0.79^{b}$ & $1.41^{\mathrm{c}}$ & $1.39^{c}$ & $0.28^{\mathrm{a}}$ & 0.236 & $<0.001$ \\
\hline
\end{tabular}

TBARS=Thiobarbituric acid reactive substances; *on log scale; Means within a row with different superscripts differ $(\mathrm{P}<0.05)$.

Conclusions Feeding incremental PX to grass silage-fed animals resulted in enhancement of 18:3n-3 and increased the longer chain derivatives EPA and DHA, resulting in improved P:S and n-6:n-3 ratios. Within the concentrate treatments PX also increased 18:3n-3 and EPA. The highest P:S ratios were noted on S-PXC treatment reflecting the high levels of 18:2n-6 and 18:3n-3 deposited. Under these circumstances the additional vitamin E fed helped to control oxidative stability as reflected in the lower TBARS.

Acknowledgements This work was supported by DEFRA, EBLEX, HCC, LMC and QMS, UK ("Probeef") and European Commission ProSafeBeef (FOOD-CT-2006-36241). The PX was kindly provided by Désialis-France Luzerne.

\section{References}

Kim, E.J. Scollan, N.D., Richardson, R.I., Gibson, K., Ball, R. and Coulmier, D. 2008. Proceedings of the British Society of Animal Science, 76. 